\title{
A Model Describing Debaryomyces hansenii Growth and Substrate Consumption During a Smear Soft Cheese Deacidification and Ripening
}

\author{
M. H. Riahi, I. C. Trelea, ${ }^{1}$ D. Picque, M.-N. Leclercq-Perlat, A. Hélias, and G. Corrieu \\ UMR782 Génie et Microbiologie des Procédés Alimentaires, AgroParisTech, 1 av. Lucien Bretigtnères, BP 01, \\ 78850 Thiverval-Grignon, France
}

\begin{abstract}
A mechanistic model for Debaryomyces hansenii growth and substrate consumption, lactose conversion into lactate by lactic acid bacteria, as well as lactose and lactate transfer from the core toward the rind was established. The model described the first step (14 d) of the ripening of a smear soft cheese and included the effects of temperature and relative humidity of the ripening chamber on the kinetic parameters. Experimental data were collected from experiments carried out in an aseptic pilot scale ripening chamber under 9 different combinations of temperature $\left(8,12\right.$, and $\left.16^{\circ} \mathrm{C}\right)$ and relative humidity $(85,93$, and $99 \%)$ according to a complete experimental design. The model considered the cheese as a system with 2 compartments (rind and core) and included 5 state evolution equations and 16 parameters. The model succeeded in predicting $D$. hansenii growth and lactose and lactate concentrations during the first step of ripening (curd deacidification) in core and rind. The nonlinear data-fitting method allowed the determination of tight confidence intervals for the model parameters. The residual standard error (RSE) between model predictions and experimental data was close to the experimental standard deviation between repeated experiments.
\end{abstract}

Key words: mechanistic model, curd deacidification, smear soft cheese ripening, dynamic model

\section{INTRODUCTION}

Mathematical modeling techniques are being applied to food microbiology problems with increasing frequency. The main objective of these models is to describe microbial growth, substrate consumption, and product generation as a function of environmental process conditions. Such models are useful for gaining insight not only into the mechanisms involved, the quan-

Received June 8, 2006.

Accepted December 21, 2006.

${ }^{1}$ Corresponding author: cristian.trelea@agroparistech.fr tification of various aspects and hypothesis testing, but also for process optimization and improving product quality. According to the objectives, 2 main approaches to modeling may be adopted:

1) Black box models (empirical or data based models). This approach establishes models ensuring a statistical correlation of the experimental data without consideration of the phenomena involved.

2) Mechanistic models based on the underlying biology, chemistry, and physics governing the considered process. These models are generally expressed as algebraic, ordinary, or partial differential equations.

Several models, dealing with some aspects of the cheese ripening, have been proposed. A summary of these models is presented below according to increasing order of complexity.

Empirical models were adopted by several authors. Frau et al. (1999) evaluated the chemical characteristics of Mahon cheeses using principal component analyses. These authors have found statistically significant differences between cheeses in terms of moisture and NPN contents; these differences were found to be independent of the manufacturing methodology (industrial or traditional). On the contrary, a significant difference was observed for ash and fat contents between industrial and traditional cheeses. Lues and Bekker (2002) used regression modeling to define the patterns of organic acid concentrations during Cheddar cheese ripening. They proposed 9 equations giving the organic acid concentration according to the maturation time with a correlation coefficient $\left(\mathrm{R}^{2}\right)$ ranging from 0.91 to 0.99 . A collective representation of the production of organic acids during maturation was also given. Poveda et al. (2004) applied least squares regression to predict the ripening time of Manchego cheeses based on some physicochemical parameters. They proposed an empirical equation with $\mathrm{pH}$, water activity, and $\mathrm{DM}$ values as parameters to predict the ripening time. Bonaïti et al. (2004) proposed polynomial models to quantify the effects of temperature and relative humidity $(\mathbf{R H})$ on 
kinetic descriptors of curd deacidification by Debaryomyces hansenii during smear soft cheeses ripening. These authors showed that the best ripening conditions to achieve an optimum between deacidification and appearance of cheeses were $12^{\circ} \mathrm{C}$ and $95 \pm 1 \% \mathrm{RH}$. Leclercq-Perlat et al. (2004) established statistically significant relationships between the different microbiological and biochemical changes during Camemberttype cheese ripening. They found that the microorganism concentrations were well correlated with the carbon substrate concentrations in cheese core and rind. Surface $\mathrm{pH}$ was significantly related to $\mathrm{NH}_{3}$ concentration and to Penicillium camemberti growth. These empirical models may constitute a basis on which to build mechanistic models.

Artificial neural networks are used to describe complex nonlinear relationships between inputs and outputs, regardless of the underlying phenomena. This approach is often used in industrial contexts due to its ability to be easily integrated in a procedure of process control. Hongxu and Gunasekaran (1998) simulated the rheological characteristics of Swiss cheeses using composition and $\mathrm{pH}$ measurements as inputs of their model. Paquet et al. (2000) modeled the final $\mathrm{pH}$ of Cheddar cheeses from industrial production using ingredient compositions and other processing variables as inputs. In 2004, an artificial neural network model having several operating conditions and culture measurements as inputs was developed and enabled successful prediction of the final process time of the acidification step and the optimal timing for the rennet addition for successful cheese production (Horiuchi et al., 2004). Recently, Jimenez-Marquez et al. (2005) published a neural network model based on cheese-making knowledge to predict moisture at the end of the ripening stirred-curd Cheddar cheese.

Mechanistic models, in addition to their ability to simulate the behavior of the process, contribute to the understanding of the physical, chemical, and biological phenomena involved. They are based on the underlying laws governing the process behavior. According to this approach, Biazar et al. (2003) proposed a kinetic model for the lactic acid production through submerged fermentation of whey using Lactobacillus helveticus. This model accounted for the effect of substrate limitation, substrate inhibition, and maintenance energy on the cell growth, substrate utilization, and lactic acid production during the fermentation process. Gerla and Rubiolo (2003) studied the diffusion phenomena during Pategras cheese ripening. They proposed a deterministic model predicting the effective diffusion coefficients of $\mathrm{NaCl}$, lactic acid, and water. Pajonk et al. (2003) investigated the heat transfer that takes place during Emmental ripening. Values of thermal diffusivity, con- ductivity, and specific heat were measured. Then, a heat transfer model was built according to physical laws and the experimental values previously determined. Recently, Aldarf et al. (2006) proposed a model simulating substrate and metabolite diffusion within a cheeselike medium in relation to Penicillium camemberti growth. They showed that limitations in carbonaceous substrate diffusion were not involved in the exponential growth, whereas nitrogen diffusion limitation accounted for the growth stop.

The aim of the present study was to develop a methodology that would contribute to the understanding of $D$. hansenii growth and its lactose and lactate consumption during the deacidification step of a smear soft cheese ripening interacting with changing environmental factors. To meet this goal, a mechanistic model was built and validated based on experimental data. The adopted experimental approach consisted on manufacturing Munster-type cheeses at a pilot scale. Then, the cheeses were ripened during $14 \mathrm{~d}$ in a ripening chamber with controlled temperature and relative humidity.

\section{MATERIALS AND METHODS}

\section{Experiments}

In this study, smear soft cheeses (Munster type) were prepared from pasteurized milk. Samples of pasteurized milk were plated on specific media (yeast extract glucose chloramphenicol, brain heart infusion; and de Man, Rogosa, Sharpe; Biokar, Paris, France) to check that no other strains were present in the milk before its inoculation with the lactic acid bacteria $(\mathbf{L A B})$ and the ripening flora. A commercial preparation of mesophilic LAB (CHN11, Chr. Hansen, Arpajon, France) was applied. Although the microflora of smear soft cheese is more complex (Bockelmann and HoppeSeyler, 2001), a simple ripening flora composed of 2 strains was used: Debaryomyces hansenii (304 from the local strain collection at Génie et Microbiologie des Procédés Alimentaires), a yeast known for its curd neutralizing activity, and Brevibacterium aurantiacum (ATCC 9175), a surface bacterium known as typical for soft smear cheeses (Rattray and Fox, 1999). Although recent studies (Eliskases-Lechner and Ginzinger, 1995; Bockelmann et al., 2005) showed that Brevibacterium spp. did not represent the main part of bacterial flora, $B$. aurantiacum was used in this work because it is responsible for the typical appearance and aroma development of the Munster-type cheeses. Cheese making and ripening were carried out under aseptic conditions as described by Leclercq-Perlat et al. (2000). Each cheese obtained weighed $300 \pm 20 \mathrm{~g}$; its diameter and thickness were 110 and $30 \mathrm{~mm}$, respectively. Temperature $(\theta)$ and $\mathrm{RH}$ of the ripening chamber were measured 
Table 1. The 2-factor, 3-level complete factorial experimental design $\left(3^{2}\right)$ according to which runs were carried out in a controlled ripening chamber $^{1}$

\begin{tabular}{|c|c|c|c|}
\hline \multirow{2}{*}{$\begin{array}{l}\text { Relative } \\
\text { humidity } \\
\text { (RH) }\end{array}$} & \multicolumn{3}{|c|}{ Temperature } \\
\hline & Low level & Medium level & High level \\
\hline High & $8^{\circ} \mathrm{C} ; 99 \% \mathrm{RH}^{\mathrm{C}}$ & $12^{\circ} \mathrm{C} ; 99 \% \mathrm{RH}^{\mathrm{C}}$ & $16^{\circ} \mathrm{C} ; 99 \% \mathrm{RH}^{\mathrm{C}}$ \\
\hline Medium & $8^{\circ} \mathrm{C} ; 93 \% \mathrm{RH}^{\mathrm{V}}$ & $\begin{array}{l}12^{\circ} \mathrm{C} ; 93 \% \mathrm{RHa}^{\mathrm{C}} \\
12^{\circ} \mathrm{C} ; 93 \% \mathrm{RHb}^{\mathrm{V}} \\
12^{\circ} \mathrm{C} ; 93 \% \mathrm{RHc}^{\mathrm{V}}\end{array}$ & $16^{\circ} \mathrm{C} ; 93 \% \mathrm{RH}^{\mathrm{V}}$ \\
\hline Low & $8^{\circ} \mathrm{C} ; 85 \% \mathrm{RH}^{\mathrm{C}}$ & $12^{\circ} \mathrm{C} ; 85 \% \mathrm{RH}^{\mathrm{V}}$ & $16^{\circ} \mathrm{C} ; 85 \% \mathrm{RH}^{\mathrm{C}}$ \\
\hline
\end{tabular}

using a combined sensor (Vaissala, Dewpoint transmitter HMP 243, Etoile International, Paris, France).

On the first day of ripening (d 1), temperature and $\mathrm{RH}$ of the ripening chamber remained constant at 12 $\pm 1^{\circ} \mathrm{C}$ and $85 \pm 2 \%$, respectively. Then, from $\mathrm{d} 2$ to 14 , conditions were fixed at defined values $\left(8,12\right.$, or $\left.16^{\circ} \mathrm{C}\right)$ and $(85,93$, or $99 \% \mathrm{RH})$ according to a complete factorial experimental design. The run carried out under the central conditions of the experimental design $\left(12^{\circ} \mathrm{C}\right.$ and 93\% $\mathrm{RH}$ ) was repeated 3 times (runs designated as a, $\mathrm{b}$, and c). In this way, 11 runs were conducted under 9 conditions of temperature and $\mathrm{RH}$ (Table 1). Total renewal of the gaseous atmosphere (period for total renewal $=2 \mathrm{~h}$ ) was applied during the whole ripening process. On $d$, the cheeses were turned. On d 14, cheeses were wrapped and removed from the ripening chamber to carry on their ripening at $4^{\circ} \mathrm{C}$ until d 42 . In this study, only the first $14 \mathrm{~d}$ were considered, with particular attention paid to the phenomenon of curd neutralization (deacidification). One cheese per experimental design condition was sampled daily, except on $\mathrm{d} 1,6$, and 10, when 2 cheeses were sampled. Concentrations of $D$. hansenii total cells, $B$. aurantiacum viable cells, lactose, and lactate were determined in the core and in the rind, as described by Leclercq-Perlat et al. (2000).

\section{Cheese Compartments}

Cheeses were divided into rind and core as shown in Figure 1. The compartment volumes were designated $V_{C}$ for the core and $V_{R}$ for the rind. The volume fraction, $\tau_{C}$, of the core was given by:

$$
\tau_{C}=\frac{V_{C}}{V_{R}+V_{C}}=0.66
$$

and the volume fraction of the rind, $\tau_{R}$, was:

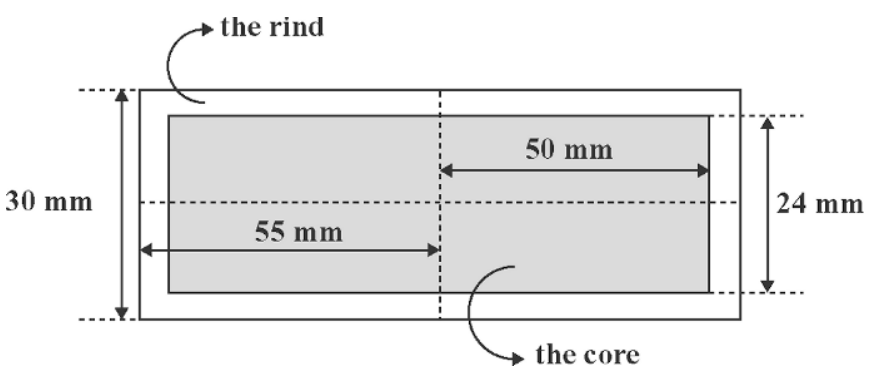

Figure 1. Schematic representation (definition and size) of the 2 cheese compartments (core and rind).

$$
\tau_{R}=1-\tau_{C}=0.34
$$

\section{Basic Modeling Assumptions}

Debaryomyces hansenii. As reported by LeclercqPerlat et al. (2004), in liquid medium and under aerobic conditions, $D$. hansenii simultaneously used lactose and lactate as substrate. Moreover, its growth rate was higher in the presence of lactose than in a lactose-lactate mixture and much higher than when in the presence of lactate alone. Bonaïti et al. (2004) investigated $D$. hansenii growth on the rind (its concentration is 100 times higher in the rind than in the core) in relation to ripening time of a smear soft cheese as well as the evolution of lactose and of lactate concentrations in the rind and in the core of the same set of cheeses. Figure 2 summarizes the evolution of these concentrations. According to the results of Bonaïti et al. (2004), parallelism was noted between $D$. hansenii growth and its substrate consumption, as follows. Debaryomyces hansenii growth can be roughly divided into 4 phases (Figure 2): phase I between $\mathrm{d} 1$ and 4 (the exponential growth phase); phase II between $d 4$ and 10 (growth deceleration phase); phase III between d 10 and 14 (stationary phase); and phase IV, which was performed out of the ripening chamber, at $4^{\circ} \mathrm{C}$ after cheese wrapping, and was not considered in this study.

During the first phase (from d 1 to 4 ) it was assumed that $D$. hansenii used lactose as a carbon source for growth. During the growth deceleration phase (from $d$ 4 to 10) there was no more lactose in the rind, and growth of $D$. hansenii was slowed. The growth rate was probably limited by lactose diffusion from core to rind. From d 10 to 14 (the stationary phase), D. hansenii growth stopped and there was no more lactose in rind or in the core. However, lactate was continuously consumed by $D$. hansenii.

These observations lead to the assumption that $D$. hansenii used lactose as the carbon source for growth and lactate for its maintenance. 


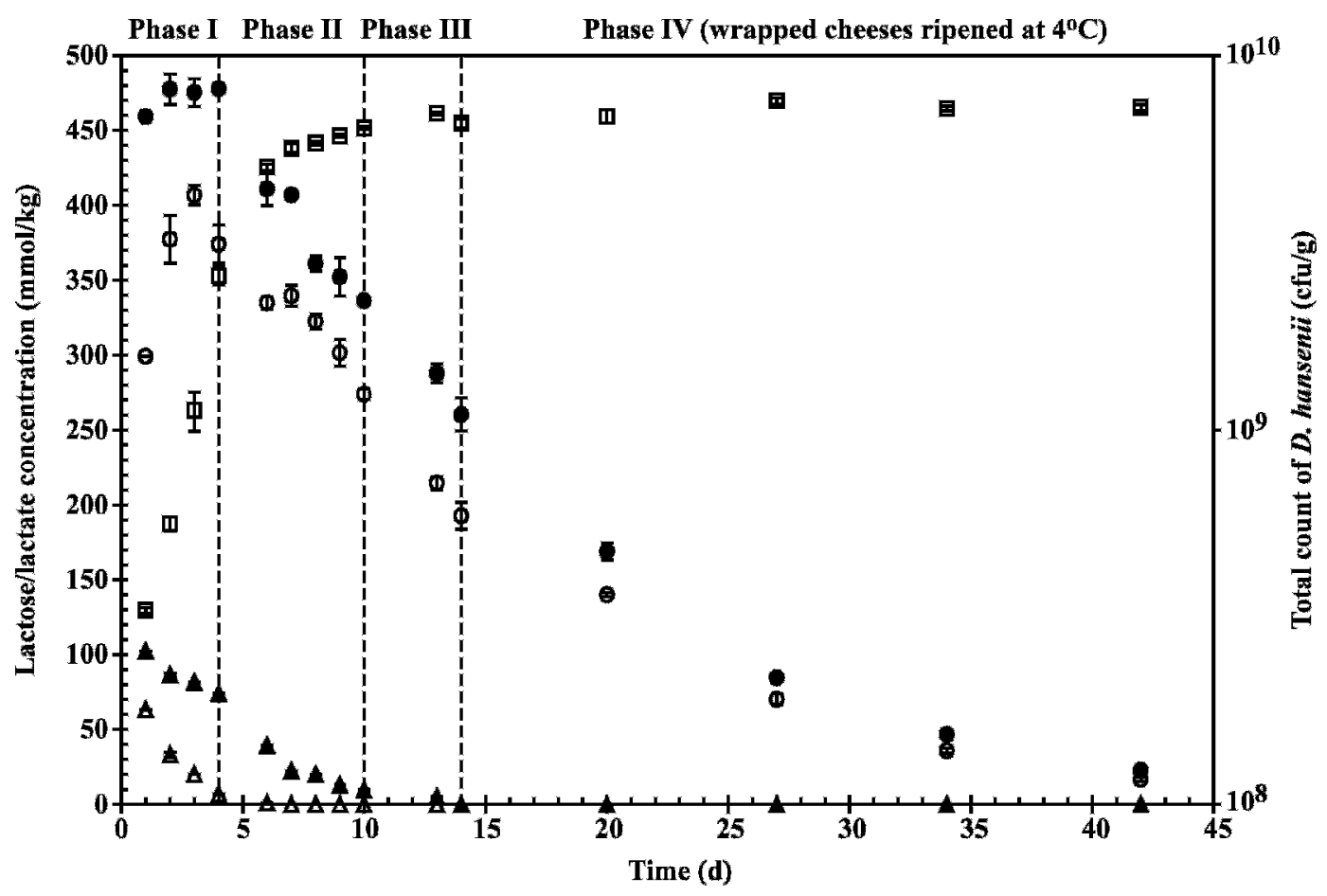

Figure 2. Debaryomyces hansenii growth $(\square)$, concentration of lactose in the rind $(\triangle)$ and in the core $(\mathbf{\Delta})$, and concentration of lactate in the rind $(\bigcirc)$ and in the core $(\bullet)$ as a function of the ripening time of a smear soft cheese (adapted from Bonaïti et al., 2004 with permission). Phases I (exponential growth of $D$. hansenii), II (growth deceleration), and III (stationary phase) were performed under controlled conditions of temperature and relative humidity in the ripening chamber. Phase IV concerned wrapped cheeses and was not considered in this study.

Brevibacterium aurantiacum. In the considered experiments, $B$. aurantiacum did not grow significantly from $\mathrm{d} 1$ to 15 (wrapping day). Its viable cell concentration remained low and close to $10^{7} \mathrm{cfu} / \mathrm{g}$, except for the runs carried out at $85 \% \mathrm{RH}$, when the viable cell concentraion decreased. Consequently, B. aurantiacum was not considered for modeling.

$\boldsymbol{L A B}$. Lactic acid bacteria were present in the rind and the core. During cheese ripening in the chamber, LAB concentration was measured on 2 runs $(99 \% \mathrm{RH}$ and $16^{\circ} \mathrm{C} ; 93 \% \mathrm{RH}$ and $12^{\circ} \mathrm{C}$ ) and found to be essentially constant between $1.10^{9}$ and $2.10^{9} \mathrm{cfu} / \mathrm{g}$, confirming the findings in the literature (Hassouna and Guizani, 1995; Lortal and Chapot-Chartier, 2005). It was thus assumed that LAB concentration remains constant during the cheese ripening. The main role of LAB during this period is the conversion of lactose into lactate.

Lactose. Lactose is converted into lactate by the LAB in the core and rind. Lactose is also consumed by $D$. hansenii at the cheese surface. In addition, lactose is transferred from the core toward the rind due to a concentration gradient (Leclercq-Perlat et al., 2000).

Lactate. Lactate is produced by the LAB in the core and rind. It is transferred toward the rind due to a concentration gradient, where it is consumed by $D$. hansenii.
These assumptions allowed us to build a mechanistic model composed of 5 differential equations describing the evolution of $D$. hansenii, lactose, and lactate concentrations in the rind and core during ripening.

\section{Model Equations}

Concentration of $\boldsymbol{D}$. hansenii. The growth rate of $D$. hansenii was modeled by the classical Monod law, taking into account the fact that the limiting substrate was lactose, as discussed above:

$$
\frac{d X}{d t}=\mu_{\max } \cdot \frac{L o_{R}}{k s_{L o(D h)}+L o_{R}} \cdot X
$$

where $\mu_{\max }$ is the maximum specific growth rate of $D$. hansenii $\left(\mathrm{d}^{-1}\right), L o_{R}$ is the lactose concentration in the rind $(\mathrm{mmol} / \mathrm{kg}), k s_{L o(D h)}$ is $D$. hansenii saturation constant for lactose $(\mathrm{mmol} / \mathrm{kg})$, and $X$ is the total cell concentration of $D$. hansenii $\left(10^{8} \mathrm{cfu} / \mathrm{g}\right)$.

Concentration of Lactose. During ripening, the lactose concentration in the core depends on the amount transferred to the rind, and on the amount consumed by the LAB in this compartment (in the core, lactose consumption by $D$. hansenii is negligible compared with that by LAB). The transfer rate of lactose from the 
core toward the rind was assumed proportional to the concentration difference between these 2 compartments. Lactose consumption by LAB was described by a Monod-like model taking into account the fact that the LAB population was constant during ripening. The mass balance of lactose in the core was thus written as:

$$
\begin{gathered}
\frac{d L o_{C}}{d t}=-\frac{K_{L o} \cdot\left(L o_{C}-L o_{R}\right)}{\tau_{C}} \\
-v_{\max } \cdot \frac{L o_{C}}{k s_{L o(L A B)}+L o_{C}}
\end{gathered}
$$

where $K_{L o}$ is the lactose transfer coefficient between the core and the rind $\left(\mathrm{d}^{-1}\right), \tau_{C}$ is the volume fraction of the core (dimensionless), $L o_{C}$ is the lactose concentration in the core $(\mathrm{mmol} / \mathrm{kg}), L o_{R}$ is the lactose concentration in the rind $(\mathrm{mmol} / \mathrm{kg}), v_{\max }$ is the $\mathrm{LAB}$ maximum specific lactose consumption rate $(\mathrm{mmol} / \mathrm{kg} \cdot \mathrm{d})$ and $k s_{L o(L A B)}$ is the LAB saturation constant for lactose ( $\mathrm{mmol} / \mathrm{kg})$.

Similarly to the core, the lactose concentration in the rind depends on the amount transferred from the core and on the amount consumed by the microorganisms evolving in the rind. In addition to LAB, D. hansenii also uses lactose as substrate for its growth. So, the evolution rate of the lactose in the rind was described as follows:

$$
\begin{gathered}
\frac{d L o_{R}}{d t}=\frac{K_{L o} \cdot\left(L o_{R}-L o_{S}\right)}{\tau_{R}} \\
-v_{\max } \cdot \frac{L o_{R}}{k s_{L o(L A B)}+L o_{R}} \\
-\frac{1}{Y_{X / L o}} \cdot \mu_{\max } \cdot \frac{L o_{R}}{k s_{L o(D h)}+L o_{R}} \cdot X
\end{gathered}
$$

where $Y_{X / L o}$ is the yield coefficient for $D$. hansenii growth on lactose $\left(10^{11} \mathrm{cfu} / \mathrm{mmol}\right)$.

It should be noted that the model equations [Eq. 3 to 5] were applied to phases I through III described in Figure 2. The differences between phases mainly arise because of different values of available lactose concentration: not limiting in the core or rind in phase I; limiting in the rind only in phase II; and absence of lactose in phase III.

Concentration of Lactate. The lactate concentration in the core depends on the amount transferred to the rind on one side, and on the amount produced by the LAB from lactose conversion on the other side. So, the evolution rate of the lactate in the core was described as:

$$
\begin{gathered}
\frac{d L a_{C}}{d t}=-\frac{K_{L a} \cdot\left(L a_{C}-L a_{R}\right)}{\tau_{C}} \\
+Y_{L a / L o} \cdot v_{\max } \cdot \frac{L o_{C}}{k s_{L o(L A B)}+L o_{C}}
\end{gathered}
$$

where $Y_{L a / L o}$ is the yield coefficient for lactose-lactate conversion (mmol of lactate/mmol of lactose).

In the rind, the lactate concentration, in addition to amount transferred from the core and to that produced by the LAB, depends on the amount consumed by $D$. hansenii. So, the evolution of the lactate in the rind was written as:

$$
\begin{aligned}
& \frac{d L a_{R}}{d t}=\frac{K_{L a} \cdot\left(L a_{C}-L a_{R}\right)}{\tau_{R}}+Y_{L a / L o} \cdot v_{\max } \\
& \cdot \frac{L o_{R}}{k s_{L o(L A B)}+L o_{R}}-m_{\max } \cdot \frac{L a_{R}}{k s_{L a}+L a_{R}} \cdot X
\end{aligned}
$$

where $m_{\max }$ is the maintenance coefficient (mmol/10 11 $\mathrm{cfu} \cdot \mathrm{d})$.

Temperature and $\boldsymbol{R H}$ Effects. To account for the effects of temperature and $\mathrm{RH}$ on the kinetic parameters $\left(\mu_{\max }, v_{\max }\right.$, and $\left.m_{\max }\right)$, linear relationships of the following form were used:

$$
P=P_{\text {central }}+\theta_{P}(\theta-12)+R H_{P}(R H-93) .
$$

The generic parameter $P$ is one of $\mu_{\max }, v_{\max }$ and $m_{\max }$; $P_{\text {central }}$ is the parameter value for runs carried out under the central conditions of the experimental design $\left(12^{\circ} \mathrm{C}\right.$, $93 \% \mathrm{RH}), \theta_{P}$ is the effect of temperature on the considered parameter $\left(1 /{ }^{\circ} \mathrm{C}\right)$, and $R H_{P}$ is the effect of relative humidity $(1 / \%)$.

\section{Fitting the Model Parameters}

The overall model has 16 parameters. Three are kinetic parameters $\left(\mu_{\max }, v_{\max }, m_{\max }\right), 6$ represent temperature and $\mathrm{RH}$ effects on these kinetic parameters $\left(\theta_{\mu \max }\right.$, $\left.\theta_{v \max }, \theta_{m \max }, R H_{\mu \max }, R H_{v \max }, R H_{\text {max }}\right), 3$ describe the substrate limitation $\left(k s_{L o(D h)}, k s_{L o(L A B)}, k s_{L a}\right), 2$ describe the transfer of lactose and lactate from the core toward the rind $\left(K_{L o}, K_{L a}\right)$, and 2 represent the conversion yield of lactate from lactose and $D$. hansenii cell production yield from lactose $\left(Y_{L a / L o}, Y_{X / L o}\right)$, respectively.

The parameters were determined with a data-processing program developed under Matlab R14 (The MathWorks Inc., Natick, MA). Their values were calculated using a nonlinear least squares data-fitting by the Levenberg-Marquardt method (Marquardt, 1963) based on the experimental data from 6 of 11 runs (called calibration runs), then they were validated in the other 5 runs (called validation runs; Table 1). Parameter fit- 
ting was performed using all 6 calibration runs and all available measurements $(D$. hansenii, lactose, and lactate concentrations) simultaneously. To balance the weight of the various measurements during the fitting process, the following scaling factors were applied: $1 / 4$ for the logarithm of the $D$. hansenii concentration, $1 /(150 \mathrm{mmol} / \mathrm{kg}$ ) for the lactose concentration (rind and core), and $1 /(600 \mathrm{mmol} / \mathrm{kg}$ ) for the lactate concentration (rind and core).

The uncertainty on the parameter values was expressed by a confidence interval at $95 \%$ calculated using the so-called local information matrix (Bury, 1999) obtained during the model-fitting process. The quality of the fit was assessed by the residual standard error (RSE) between experimental and predicted data:

$$
R S E=\sqrt{\frac{1}{n} \sum_{i=1}^{n}\left(\operatorname{sim}_{i}-\exp _{i}\right)^{2}}
$$

where $\operatorname{sim}$ is the simulated data, $\exp$ is the experimental data, and $n$ is the number of samples.

In the special case of the saturation constants $\left(k s_{L a}\right.$, $\left.k s_{L o(L A B)}, k s_{L o(D h)}\right)$ that cannot be determined reliably in the case of batch fermentations (Bastin and Dochain, 1990), their values were set according to the literature. Saturation constants were calculated by different methods for some LAB strains (Schepers et al., 2002; Biazar et al., 2003) and some yeast strains (Ghaly and ElTaweel, 1997; Barba et al., 2001; Ghaly et al., 2005). All of these authors reported that these constants were highly dependent on the microorganism strain and on the $\mathrm{pH}$ of the medium. Consequently, the saturation constants adopted for the present study were typical values. The $\mathrm{LAB}$ saturation constant for lactose, $k s_{\mathrm{Lo}(L A B)}$, was set to $10 \mathrm{mmol} / \mathrm{kg}$ and the $D$. hansenii saturation constant for lactose, $k s_{L o(D h)}$, and for lactate, $k s_{L a}$, were set to $20 \mathrm{mmol} / \mathrm{kg}$.

In addition to the model parameters, the solution of the differential equations [Eq. 3 to 7] requires the values of the $D$. hansenii, lactose, and lactate concentrations ( $X, L o_{C}, L o_{R}, L a_{C}$, and $L a_{R}$, respectively) at the beginning of the ripening phase ( $d 1)$. Two cheeses were sampled on $d 1$ in each run and the average of the 2 measurements was used as the initial value for the model simulations.

\section{RESULTS}

\section{Model Fitting}

The fitted model parameters are given in Table 2 together with their $95 \%$ confidence intervals. These confidence intervals are quite small, indicating that model parameters can be determined accurately from the se-
Table 2. Values of the parameters obtained by nonlinear regression and their confidence intervals at the $95 \%$ level

\begin{tabular}{lll}
\hline & $\begin{array}{c}\text { Most } \\
\text { probable } \\
\text { value }\end{array}$ & $\begin{array}{c}\text { Confidence } \\
\text { interval }\end{array}$ \\
\hline Parameter $^{1}$ & 1.21 & {$[1.14 ; 1.28]$} \\
$\mu_{\max }\left(\mathrm{d}^{-1}\right)$ & 6.83 & {$[6.33 ; 7.37]$} \\
$v_{\max }(\mathrm{mmol} / \mathrm{kg} \cdot \mathrm{d})$ & 0.17 & {$[0.15 ; 0.18]$} \\
$m_{\max }\left(\mathrm{mmol} / 10^{11} \mathrm{cfu} . \mathrm{d}\right)$ & 0.08 & {$[0.07 ; 0.09]$} \\
$K_{L o}\left(\mathrm{~d}^{-1}\right)$ & 0.26 & {$[0.22 ; 0.30]$} \\
$K_{L a}\left(\mathrm{~d}^{-1}\right)$ & 2.78 & {$[2.50 ; 3.03]$} \\
$Y_{X / L o}\left(10^{11} \mathrm{cfu} / \mathrm{mmol}\right)$ & 2.72 & {$[2.48 ; 2.99]$} \\
$Y_{L a / L o}(\mathrm{mmol} / \mathrm{mmol})$ & 0.070 & {$[0.069 ; 0.071]$} \\
$\theta_{\mu \max }\left(\mathrm{d}^{-1} \cdot{ }^{\circ} \mathrm{C}\right)$ & 0.026 & {$[0.018 ; 0.034]$} \\
$R H_{\mu \max }\left(\mathrm{d}^{-1} \cdot \%\right)$ & 0.12 & {$[0.09 ; 0.14]$} \\
$\theta_{v \max }\left(\mathrm{mmol} / \mathrm{kg} \cdot \mathrm{d} \cdot{ }^{\circ} \mathrm{C}\right)$ & 0.02 & {$[0.01 ; 0.03]$} \\
$R H_{v \max }(\mathrm{mmol} / \mathrm{kg} \cdot \mathrm{d} \cdot \%)$ & 0.010 & {$[0.009 ; 0.011]$} \\
$\theta_{m \max }\left(\mathrm{mmol} / 10^{11} \mathrm{cfu} \cdot \mathrm{d} \cdot{ }^{\circ} \mathrm{C}\right)$ & 0.016 & {$[0.015 ; 0.017]$} \\
$R H_{m \max }\left(\mathrm{mmol} / 10^{11} \mathrm{cfu} \cdot \mathrm{d} \cdot \%\right)$ &
\end{tabular}

${ }^{1}$ Parameters: $\mu_{\max }=$ maximum specific growth rate of Debaryomyces hansenii; $v_{\max }=\mathrm{LAB}$ maximum specific lactose consumption rate; $m_{\max }=$ maintenance coefficient; $K_{L o}=$ lactose transfer coefficient between the core and the rind; $K_{L a}=$ lactate transfer coefficient between the core and the rind; $Y_{L a / L o}=$ yield coefficient for lactose-lactate conversion; $Y_{X / L o}=$ yield coefficient for $D$. hansenii growth on lactose; $\theta_{\mu \max }, \theta_{v \max }$, and $\theta_{\text {max }}=$ effects of the temperature on $\mu_{\max }, v_{\max }$, and $m_{\max }$, respectively; $R H_{\mu \max }, R H_{v \max }$, and $R H_{m \max }=$ effects of the relative humidity on $\mu_{\max }, v_{\max }$, and $m_{\max }$, respectively.

lected calibration runs. The RSE between experimental data and model predictions were calculated for each run. It appeared that the average RSE of the validation runs were close to those of the calibration runs (Table 3 ). This shows the generalization ability of the model to other combinations of operating conditions (within the domain explored by the experimental design) not used for calibration.

Because the saturation constants were fixed according to the literature, the influence of their values on the model predictions was assessed in Table 4. As explained by Bastin and Dochain (1990), it appeared that the exact knowledge of the saturation constants is not critical. Indeed, their modification by $\pm 90 \%$ had a limited effect on the model predictions.

\section{Growth of D. hansenii}

Figure 3 shows the predicted and experimental growth curves of $D$. hansenii during ripening for the 11 runs of the experimental design. The model succeeded in simulating the 3 growth phases of $D$. hansenii: the exponential growth phase between $\mathrm{d} 1$ and 4 , the decelerating growth phase between $\mathrm{d} 4$ and 10 , and the stationary phase until $\mathrm{d} 14$. Whatever the run, the model predicted a $D$. hansenii concentration close to 7 $\times 10^{9} \mathrm{cfu} / \mathrm{g}$ at d 14 . Except for the "a" run at $12^{\circ} \mathrm{C} / 93 \%$ $\mathrm{RH}$ and the run at $16^{\circ} \mathrm{C} / 93 \% \mathrm{RH}$, the $\mathrm{RSE}$ between 
Table 3. Average residual standard error (RSE) of the calibration and validation runs together with the standard deviation (SD) between the repeated runs

\begin{tabular}{lcrr}
\hline & $\begin{array}{c}\text { Average RSE of } \\
\text { the calibration runs }\end{array}$ & \multicolumn{1}{c}{$\begin{array}{c}\text { Average RSE of } \\
\text { the validation runs }\end{array}$} & $\begin{array}{c}\text { SD between } \\
\text { the repeated runs }\end{array}$ \\
Parameter & $0.41 \pm 0.04$ & $0.47 \pm 0.02$ & $0.68 \pm 0.02$ \\
Debaryomyces hansenii growth $\left[\log _{10}(\mathrm{cfu} / \mathrm{g})\right]$ & $6.99 \pm 0.89$ & $6.65 \pm 0.55$ & $4.51 \pm 0.15$ \\
Lactose concentration in the rind $(\mathrm{mmol} / \mathrm{kg})$ & $12.58 \pm 0.31$ & $3.95 \pm 0.46$ & $5.40 \pm 0.35$ \\
Lactose concentration in the core $(\mathrm{mmol} / \mathrm{kg})$ & $42.72 \pm 1.53$ & $36.82 \pm 1.15$ & $45.33 \pm 1.28$ \\
Lactate concentration in the rind $(\mathrm{mmol} / \mathrm{kg})$ & $38.68 \pm 1.94$ & & $50.47 \pm 2.22$ \\
Lactate concentration in the core $(\mathrm{mmol} / \mathrm{kg})$ & & & \\
\hline
\end{tabular}

experimental data and predicted $D$. hansenii growth curves ranged between 0.09 and $0.53 \log _{10}(\mathrm{cfu} / \mathrm{g})$, which is acceptable for a microbial growth estimation. Moreover, the average RSE of the validation runs was smaller than standard deviation of the 3 repetitions of the run carried out under the central conditions of the experimental design $\left(12^{\circ} \mathrm{C}\right.$ and $93 \% \mathrm{RH}, \mathrm{a}, \mathrm{b}$, and $\mathrm{c}$; Table 3).

For the runs carried out under the central conditions of the experimental design, the determined value of the maximum specific growth rate $\mu_{\max }$ was equal to 1.21 $\mathrm{d}^{-1}$ (Table 2). The response surface plots of the maximum specific growth rate of $D$. hansenii $\mu_{\max }$ showed significant positive effects of temperature and relative humidity on this parameter. Its highest value was obtained for the run at $16^{\circ} \mathrm{C}$ and $99 \% \mathrm{RH}$ and was equal to $1.64 \mathrm{~d}^{-1}$; its lowest value was $0.72 \mathrm{~d}^{-1}$ obtained for the run at $8^{\circ} \mathrm{C}$ and $85 \% \mathrm{RH}$.

\section{LAB Activity}

The LAB concentration was assumed constant during the ripening phase and the model described only the ability of LAB to convert lactose into lactate. According to the adopted data-fitting method and for the runs carried out under the central conditions of the experimental design, $v_{\max }$ was equal to $6.83 \mathrm{mmol} / \mathrm{kg} \cdot \mathrm{d}$ (Table
2). The response surface plots of the LAB maximum specific lactose consumption rate, $v_{\max }$, showed that temperature and relative humidity increase had positive effects on this parameter. The temperature had stronger effect on $v_{\max }$ than the $\mathrm{RH}$. Indeed, a variation of $14 \%$ in $\mathrm{RH}$ increased the $v_{\max }$ value only by $5 \%$, whereas a variation of $8^{\circ} \mathrm{C}$ in temperature increased the $v_{\max }$ value by $15 \%$. The highest value of $v_{\max }$ was obtained for the run at $16^{\circ} \mathrm{C}$ and $99 \% \mathrm{RH}$ and was close to $7.4 \mathrm{mmol} / \mathrm{kg} \cdot \mathrm{d}$; its lowest value was close to $6.2 \mathrm{mmol} /$ $\mathrm{kg} \cdot \mathrm{d}$ obtained for the run at $8^{\circ} \mathrm{C}$ and $85 \% \mathrm{RH}$. The model also indicated that the yield coefficient for lactose-lactate conversion, $Y_{L a / L o}$, of the LAB used in this study was 2.72 (Table 2 ).

\section{Evolution of Lactose Concentration}

Figure 4 shows the evolution of the predicted and experimental lactose concentration in the rind and core during ripening for the 11 runs. The lactose concentrations decreased quickly, regardless of the considered cheese compartment. Lactose was assimilated on the cheese rind and its concentration was negligible beyond d 5. The lactose concentration was greater in the core than in the rind, but the overall changes were similar. Lactose concentrations in the cheese core became negligible on d 10 to 13 . The RSE calculated between experi-

Table 4. Influence of the saturation constant values on the model predictions

\begin{tabular}{lcccccc}
\hline & & \multicolumn{5}{c}{ Variations (\%) of the average RSE ${ }^{2}$} \\
\cline { 3 - 6 } $\begin{array}{l}\text { Saturation } \\
\text { constant }^{1}\end{array}$ & $\begin{array}{c}\text { Value } \\
(\mathrm{mmol} / \mathrm{kg})\end{array}$ & $\begin{array}{c}\text { D. hansenii } \\
\text { growth }\end{array}$ & $\begin{array}{c}\text { Lactose } \\
\text { concentration } \\
\text { (rind) }\end{array}$ & $\begin{array}{c}\text { Lactose } \\
\text { concentration } \\
\text { (core) }\end{array}$ & $\begin{array}{c}\text { Lactate } \\
\text { concentration } \\
\text { (rind) }\end{array}$ & $\begin{array}{c}\text { Lactate } \\
\text { concentration } \\
\text { (core) }\end{array}$ \\
\hline$k s_{L o(D h)}$ & 2 & -2.1 & 0.5 & 0.3 & 0.7 & -0.7 \\
$k s_{L o(L A B)}$ & 1 & 0.2 & 0.4 & 0.6 & 0.2 & 0.3 \\
$k s_{L a}$ & 2 & 0.0 & 0.0 & 1.0 & 0.2 & -1.4 \\
$k s_{L o(D h)}$ & 38 & 2.4 & 1.6 & 0.1 & 1.0 & 1.5 \\
$k s_{L o(L A B)}$ & 19 & -0.9 & 1.0 & -0.5 & -0.4 & 0.8 \\
$k s_{L a}$ & 38 & 0.0 & 0.0 & -1.0 & 1.4 & 2.5 \\
\hline
\end{tabular}

${ }^{1}$ Constants: $k s_{L a}=$ Debaryomyces hansenii saturation constant for lactate $(\mathrm{mmol} / \mathrm{kg}) ; k s_{L o(L A B)}=\mathrm{LAB}$ saturation constant for lactose $(\mathrm{mmol} / \mathrm{kg}) ; k s_{L o(D h)}=D$. hansenii saturation constant for lactose $(\mathrm{mmol} / \mathrm{kg})$. Nominal values of $k s_{L o(D h)}, k s_{L o(L A B)}$, and $k s_{L a}$ were set at 20,10 , and $20 \mathrm{mmol} / \mathrm{kg}$, respectively.

${ }^{2}$ Variations of the average residual standard error (RSE) were established for a $90 \%$ increase and decrease of these 3 parameters. 

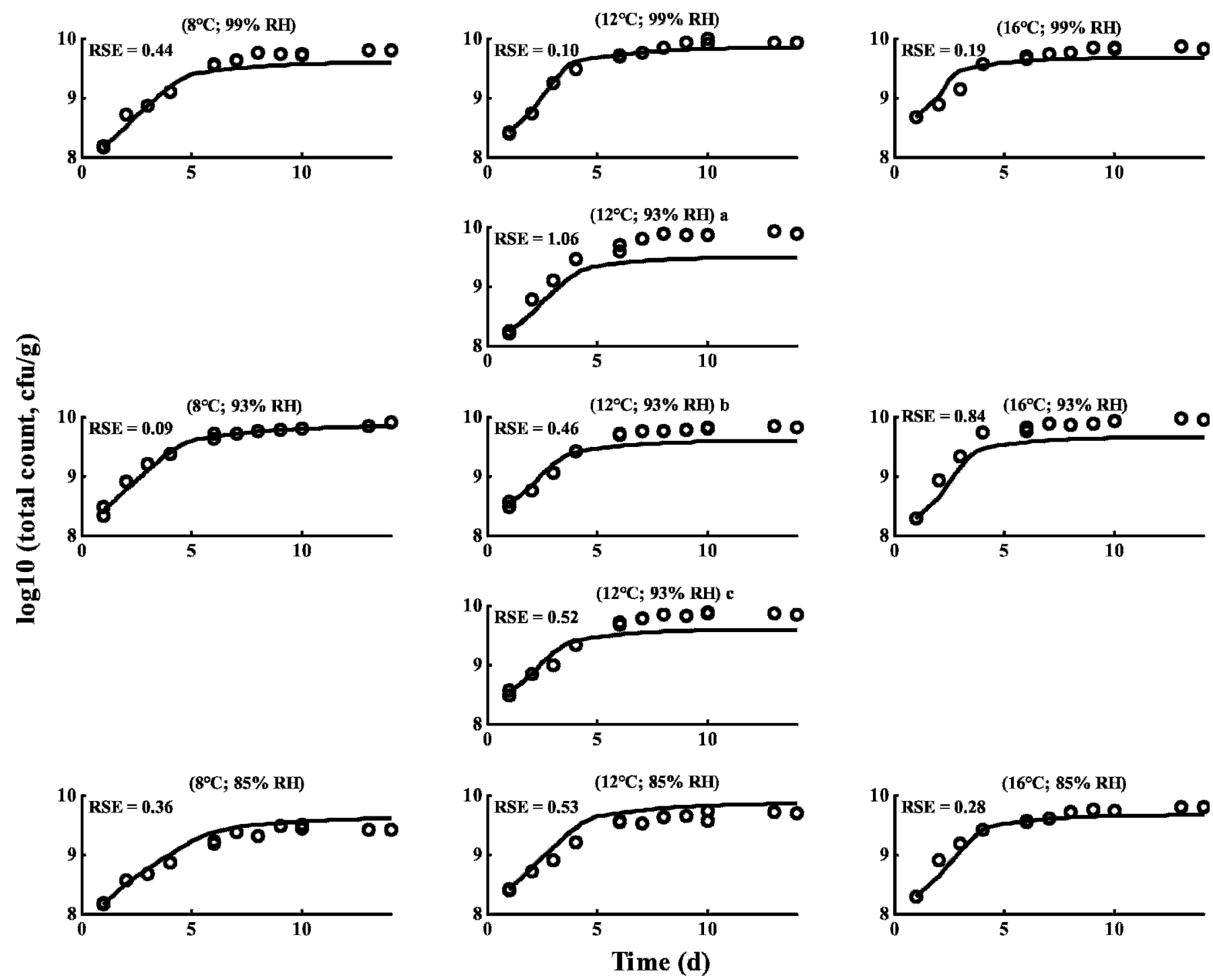

Figure 3. Experimental $(\bigcirc)$ and predicted (-) concentrations of Debaryomyces hansenii in the rind vs. ripening time according a 2factor, 3-level experimental design. The residual standard error (RSE) in $\log _{10}$ (cfu/g) was reported for each run.

mental data and predicted lactose concentrations in the rind varied between 1.94 and $15.2 \mathrm{mmol} / \mathrm{kg}$ for a variation of the rind lactose concentration between 0 and $80 \mathrm{mmol} / \mathrm{kg}$. In the core, it was noticed that the predictions of the runs at $12^{\circ} \mathrm{C} / 85 \% \mathrm{RH}$ and $12^{\circ} \mathrm{C} / 99 \%$ $\mathrm{RH}$ had the highest RSE of 22.0 and $26.4 \mathrm{mmol} / \mathrm{kg}$, respectively, with significant impact on the average RSE. For these 2 runs, the experimental data indicated a quasi-constant value of the lactose concentration in the core between $\mathrm{d} 5$ and 10 . The model was not able to simulate this unusual phenomenon, which remains unexplained. For the other runs, considering a variation of the lactose concentration between 0 and 140 $\mathrm{mmol} / \mathrm{kg}$, the values of RSE ranging between 4.29 and $15.6 \mathrm{mmol} / \mathrm{kg}$ were satisfactory, in spite of the fact that the average RSE of the validation runs was higher than the average standard deviation between the runs carried out under the central conditions of the experimental design (Table 3).

\section{Evolution of Lactate Concentration}

Figure 5 shows the evolution of the predicted and experimental lactate concentration in the rind and core during ripening for the 11 runs. In most cases, the model succeeded in simulating the initial acidification phenomenon (increase of lactate concentration) and subsequently in predicting the final lactate concentrations. Lactate concentrations increased in the core and in the rind between $d 1$ and 3 . This acidification phe- 

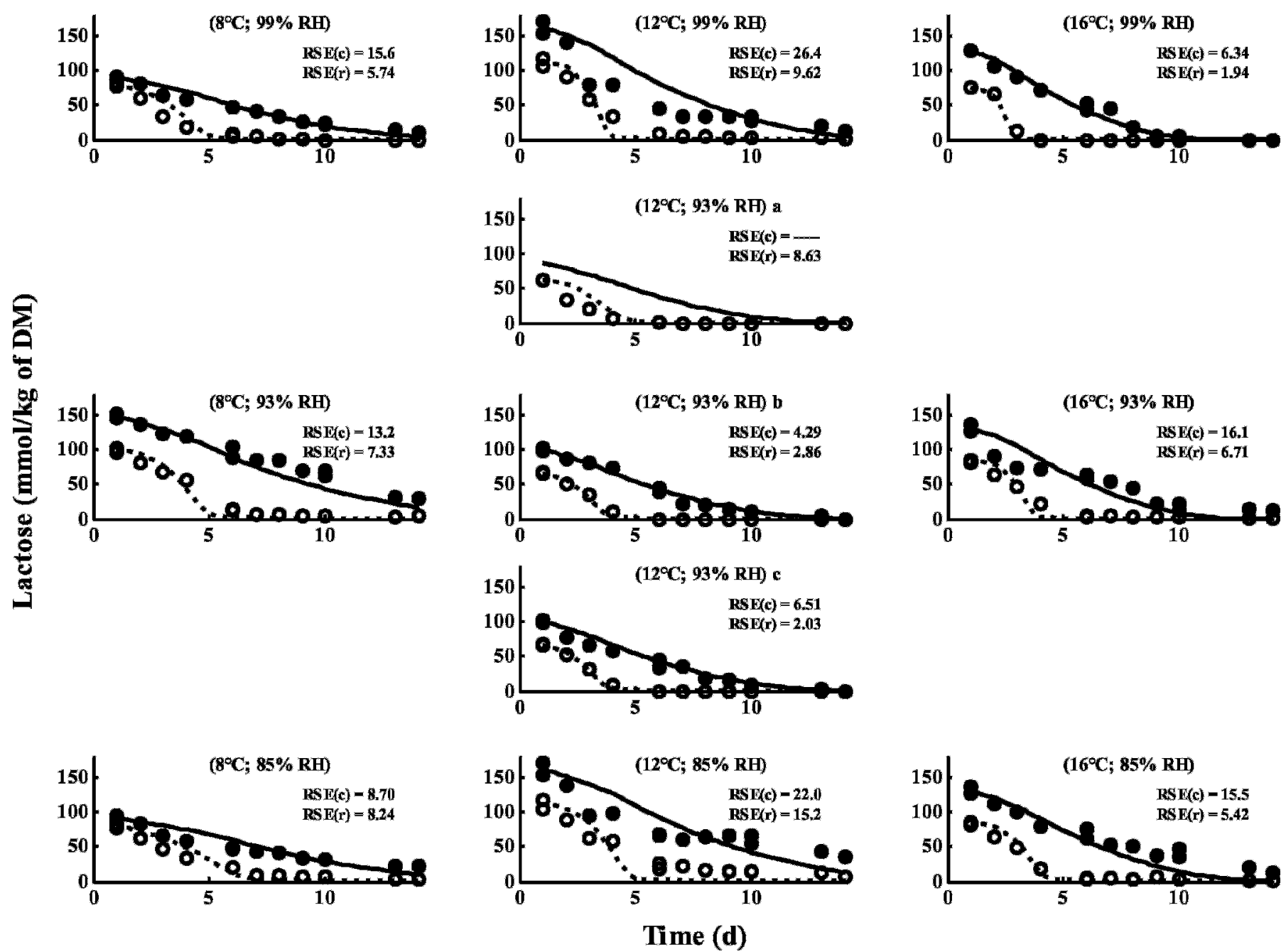

Figure 4. Experimental $(\bullet, \bigcirc)$ and predicted $(-, \cdots \cdot \cdot)$ evolution of lactose concentration vs. ripening time of a smear soft cheese according a 2-factor, 3-level experimental design in the rind $(\bigcirc, \cdots \cdot)$ and core compartments $(\bullet,-)$. For the "a" run at $12^{\circ} \mathrm{C}$ and $93 \%$ relative humidity $(\mathrm{RH})$, the experimental data of the core were not available. The residual standard error (RSE) in mmol/kg was reported for each run for the core (c) and rind (r) lactose concentrations.

nomenon was previously observed by Leclercq-Perlat et al. (2000). On d 3, the lactate concentration was maximal. Then, from d 4 to 14 , it decreased due to $D$. hansenii activity, the only microorganism able to metabolize lactate present in this study. Considering the overall variation of the lactate concentration (between 0 and $600 \mathrm{mmol} / \mathrm{kg}$ ), the calculated RSE were satisfying. For the rind the RSE ranged between 14.9 and $68.1 \mathrm{mmol} / \mathrm{kg}$, and between 23.2 and $59.9 \mathrm{mmol} /$ $\mathrm{kg}$ for the core. It was noticed that the "a" and "c" runs at $12^{\circ} \mathrm{C}$ and $93 \% \mathrm{RH}$ had the highest RSE. Moreover, the average RSE of the validation runs was smaller than the SD between the 3 repetitions of the runs carried out under the central conditions of the experimental design (Table 3).
The maintenance coefficient $m_{\max }$ (expressing the consumption of lactate by $D$. hansenii) was equal to $0.17 \mathrm{mmol} / 10^{11} \mathrm{cfu} \cdot \mathrm{d}$ (Table 2 ) for the runs carried out under the central conditions of the experimental design. The response surface plots of $m_{\max }$ showed positive effects of temperature and $\mathrm{RH}$ increase. The $\mathrm{RH}$ effect on $m_{\max }$ was stronger than the temperature effect. For example, according to Eq. 8 and Figure 6, for runs carried out at $12^{\circ} \mathrm{C}$, a variation of $\mathrm{RH}$ from 85 to $99 \%$ increased the $m_{\max }$ value 6.3 -fold, whereas for runs carried out at $93 \% \mathrm{RH}$, a variation of the temperature from 8 to $16^{\circ} \mathrm{C}$ increased the $m_{\max }$ value only 1.6 -fold. It was also noticed that for the run at $8{ }^{\circ} \mathrm{C}$ and $85 \% \mathrm{RH}$, the value of $m_{\max }$ was the smallest and close to zero $(0.002$ $\left.\mathrm{mmol} / 10^{11} \mathrm{cfu} \cdot \mathrm{d}\right)$ and that its highest value $(0.31 \mathrm{mmol} /$ 

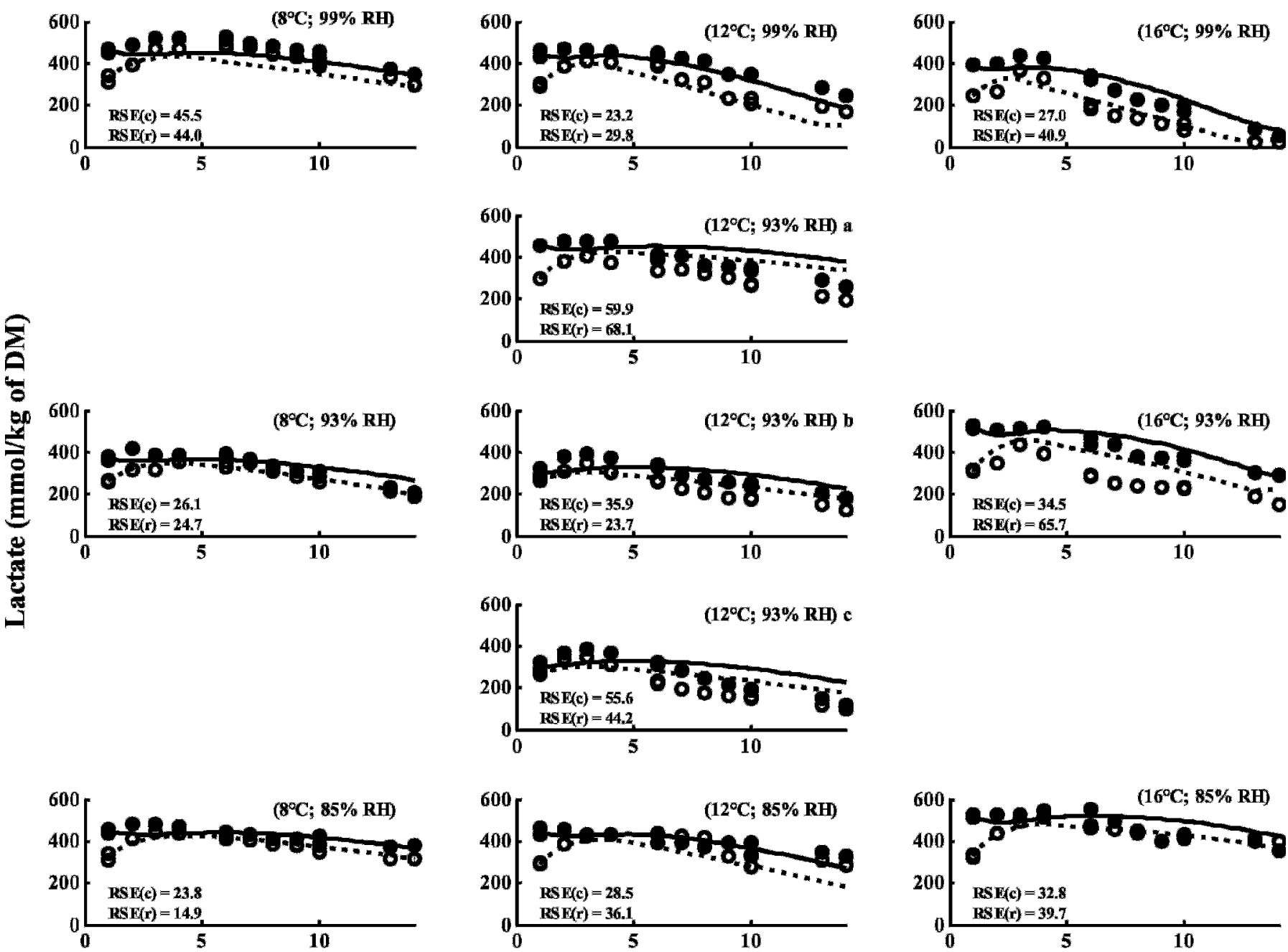

Time (d)

Figure 5. Experimental $(\bullet, \bigcirc)$ and predicted $(-, \cdots \cdot)$ evolution of lactate concentration vs. ripening time of a smear soft cheese according a 2 -factor, 3-level experimental design in the rind $(O, \cdots \cdot)$ and core compartments $(\bullet,-)$. The residual standard error $(\mathrm{RSE}) \mathrm{in} \mathrm{mmol} / \mathrm{kg}$ was reported for each run for the core (c) and rind (r) lactate concentrations.

$\left.10^{11} \mathrm{cfu} \cdot \mathrm{d}\right)$ was obtained for the run at $16^{\circ} \mathrm{C}$ and $99 \%$ $\mathrm{RH}$.

\section{Sensitivity of the Model Parameters}

To evaluate the sensitivity of the model predictions with respect to the parameter values, these values were incremented by $10 \%$. The effect of this modification on the average RSE of each simulation is shown in Table 5 . For example, it appeared that a variation of $10 \%$ of the maximum specific growth rate of $D$. hansenii would improve the average RSE of $D$. hansenii concentration by $5.7 \%$, but would worsen the RSE of the lactose concentration in the rind by $11 \%$. The same variation of the LAB-specific lactose consumption rate $v_{\max }$ mainly affected the estimation of lactose and lactate concentrations in the core, whereas the maintenance coefficient $m_{\max }$ affected the estimation of the lactate concentrations in the core and rind. As expected, Table 5 also showed that the prediction of the lactate concentration is related to the consumption rate of lactose by LAB $\left(v_{\max }\right)$ and to the yield of lactose-lactate conversion $\left(Y_{L a / L o}\right)$.

A variation of $10 \%$ of the lactose transfer coefficient, $K_{L o}$, affected the prediction of $D$. hansenii growth and of lactose concentration in the core. The variation of the lactate transfer coefficient, $K_{L a}$, only affected the values of lactate concentration in the rind.

Among the parameters expressing the effects of temperature and $\mathrm{RH}$, only $\theta_{m \max }$ and $R H_{m \max }$ significantly 
A

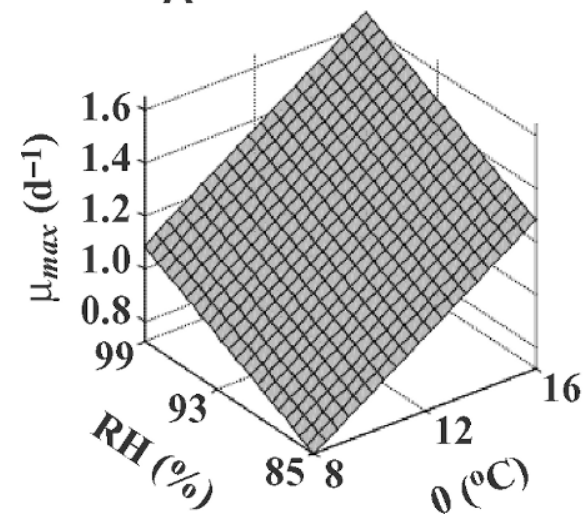

B

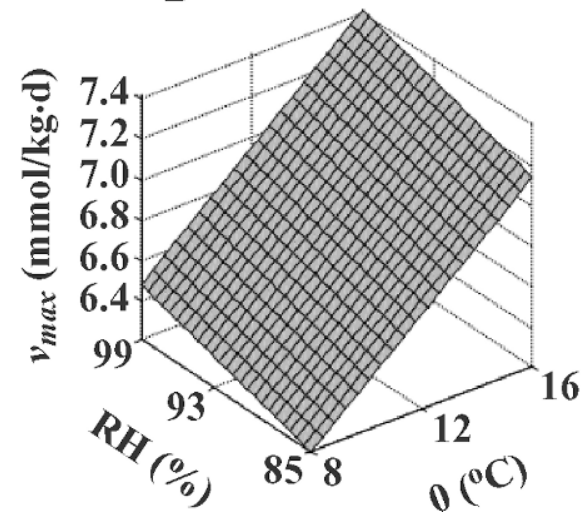

C

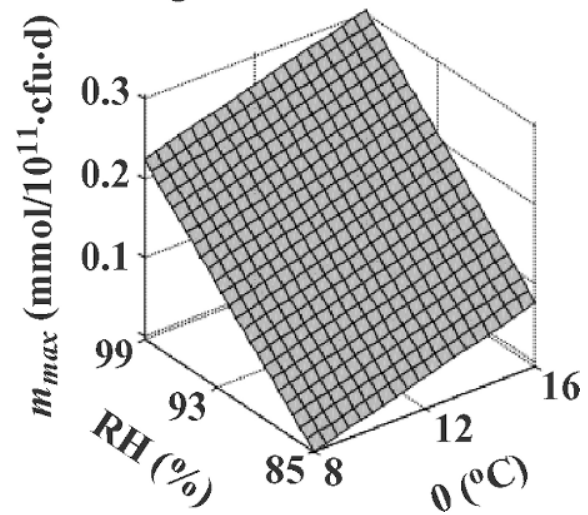

Figure 6. Response surface plots of the kinetic model parameters as a function of temperature $(\theta)$ and relative humidity $(\mathrm{RH}) . \mathrm{A}=\mu_{\mathrm{max}}$, the maximum specific growth rate of Debaryomyces hansenii $\left(\mathrm{d}^{-1}\right) ; \mathrm{B}=v_{\max }$, the maximum specific lactose consumption rate of lactic acid bacteria $(\mathrm{mmol} / \mathrm{kg} \cdot \mathrm{d})$; and $\mathrm{C}=m_{\max }$, the lactate maintenance coefficient of $D$. hansenii $\left(\mathrm{mmol} / 10^{11} \mathrm{cfu} \cdot \mathrm{d}\right)$.

changed the RSE of the lactate concentration in the core and rind.

\section{DISCUSSION}

The first days of ripening ( 1 to 4 ) corresponded to the exponential growth phase of $D$. hansenii. During this phase, $D$. hansenii used lactose as carbon source and its maximum specific growth rate was $1.21 \mathrm{~d}^{-1}$ for the runs ripened under the central conditions of the experimental design $\left(12^{\circ} \mathrm{C}\right.$ and $\left.93 \% \mathrm{RH}\right)$. This value was higher than the one given by Bonaïti et al. (2004), namely $0.81 \mathrm{~d}^{-1}$ (the value reported by those authors as $\mu_{\max }$ was in fact $\left.\mu_{\max } / \ln 10\right)$. The difference between these 2 values was due to the adopted determination method. The value reported by Bonaïti et al. (2004) represents an average growth rate calculated by linear regression between $\mathrm{d} 2$ and 4 , whereas the value re-

Table 5. Effect of a 10\% variation of the model parameters on the average residual standard error (RSE) of the model predictions

\begin{tabular}{|c|c|c|c|c|c|}
\hline \multirow[b]{2}{*}{$\begin{array}{l}\text { Incremented } \\
\text { parameter }^{1}\end{array}$} & \multicolumn{5}{|c|}{ Variations (\%) of the average RSE } \\
\hline & $\begin{array}{c}\text { D. hansenii } \\
\text { concentration }\end{array}$ & $\begin{array}{l}\text { Lactose } \\
\text { concentration } \\
\text { (rind) }\end{array}$ & $\begin{array}{c}\text { Lactose } \\
\text { concentration } \\
(\text { core })\end{array}$ & $\begin{array}{c}\text { Lactate } \\
\text { concentration } \\
\text { (rind) }\end{array}$ & $\begin{array}{c}\text { Lactate } \\
\text { concentration } \\
(\text { core })\end{array}$ \\
\hline$\mu_{\max }\left(\mathrm{d}^{-1}\right)$ & $-5.7^{2}$ & $+11.0^{2}$ & +0.1 & +0.3 & -1.3 \\
\hline$v_{\max }(\mathrm{mmol} / \mathrm{kg} \cdot \mathrm{d})$ & +1.7 & -0.7 & $+2.3^{2}$ & +0.8 & $+3.7^{2}$ \\
\hline$m_{\max }\left(\mathrm{mmol} / 10^{11} \mathrm{cfu} \cdot \mathrm{d}\right)$ & +0.0 & +0.0 & +0.3 & $-4.9^{2}$ & $+4.6^{2}$ \\
\hline$K_{L o}\left(\mathrm{~d}^{-1}\right)$ & $-4.0^{2}$ & +0.3 & $+3.1^{2}$ & -0.6 & -0.6 \\
\hline$K_{L a}\left(\mathrm{~d}^{-1}\right)$ & +0.2 & -0.2 & +0.1 & $-2.4^{2}$ & -0.8 \\
\hline$Y_{X / L o}\left(10^{11} \mathrm{cfu} / \mathrm{mmol}\right)$ & $+10.8^{2}$ & $+2.3^{2}$ & +0.2 & -0.2 & +0.9 \\
\hline$Y_{L a / L o}(\mathrm{mmol} / \mathrm{mmol})$ & +0.0 & +0.0 & +0.3 & -0.4 & $+8.5^{2}$ \\
\hline$\theta_{\mu \max }\left(\mathrm{d}^{\left.-1 \cdot{ }^{\circ} \mathrm{C}\right)}\right.$ & -0.5 & -0.5 & +0.2 & -1.2 & -0.2 \\
\hline$R H_{\mu \max }\left(\mathrm{d}^{-1} \cdot \%\right)$ & +0.1 & +0.2 & +0.3 & -1.1 & +0.8 \\
\hline$\theta_{v \max }\left(\mathrm{mmol} / \mathrm{kg} \cdot \mathrm{d} \cdot{ }^{\circ} \mathrm{C}\right)$ & +0.9 & +0.1 & +0.7 & -0.9 & +1.5 \\
\hline$R H_{v \max }(\mathrm{mmol} / \mathrm{kg} \cdot \mathrm{d} \cdot \%)$ & +0.0 & +0.2 & +0.3 & -0.2 & -0.7 \\
\hline$\theta_{\operatorname{mmax}}\left(\mathrm{mmol} / 10^{11} \mathrm{cfu} \cdot \mathrm{d} \cdot{ }^{\circ} \mathrm{C}\right)$ & +0.0 & +0.0 & +0.3 & $-3.1^{2}$ & $-2.2^{2}$ \\
\hline$R H_{m \max }\left(\mathrm{mmol} / 10^{11} \mathrm{cfu} \cdot \mathrm{d} \cdot \%\right)$ & +0.0 & +0.0 & +0.3 & $-2.7^{2}$ & $+2.2^{2}$ \\
\hline
\end{tabular}

${ }^{1}$ Parameters: $\mu_{\max }=$ maximum specific growth rate of Debaryomyces hansenii $; v_{\max }=$ LAB maximum specific lactose consumption rate; $m_{\max }=$ maintenance coefficient; $K_{L o}=$ lactose transfer coefficient between the core and the rind; $K_{L a}=$ lactate transfer coefficient between the core and the rind; $Y_{L a / L o}=$ yield coefficient for lactose-lactate conversion; $Y_{X / L o}=$ yield coefficient for $D$. hansenii on lactose; $\theta_{\mu \max }, \theta_{v \max }$, and $\theta_{m \max }=$ effects of the temperature on $\mu_{\max }, v_{\max }$, and $m_{\max }$, respectively; $R H_{\mu \max }, R H_{v \max }$, and $R H_{m \max }=$ effects of the relative humidity on $\mu_{\max }, v_{\max }$, and $m_{\max }$, respectively.

${ }^{2}$ Significant variation $(P<0.05)$. 
ported in this work is a theoretical maximal one, if no growth limitation were present [Eq. 3].

Growth of $D$. hansenii was strongly influenced by ripening temperature and $\mathrm{RH}$. Between the extreme points of the experimental design, the maximum specific growth rate value varied by almost 2 -fold.

Bonaïti et al. (2004) calculated the maximal lactose decrease rate in the core $\left(\mathbf{D}_{\mathbf{L O}}\right)$ by linear regression between $\mathrm{d} 3$ and 10 and obtained a value of $9.5 \mathrm{mmol} /$ $\mathrm{kg} \cdot \mathrm{d}$. This is $30 \%$ higher than the value of the LAB maximum lactose consumption rate $\left(v_{\max }\right)$ calculated in the present study. The discrepancy is probably because $\mathrm{D}_{\mathrm{LO}}$ was expressing the decrease in lactose concentration in the core due to both LAB consumption and transfer to the surface, rather than LAB consumption alone..

The commercial preparation of mesophilic LAB used in this study was a mixture of heterofermentative and homofermentative strains, which is consistent with the obtained $Y_{L a / L o}$ value (2.72). Indeed, if the LAB were exclusively homofermentative (producing neither $\mathrm{CO}_{2}$ nor ethanol), 1 lactose molecule would give 4 lactate molecules; thus, the value of $Y_{L a / L o}$ would be close to 4. Similarly, it would be close to 2 if the strains were exclusively heterofermentative.

Between $\mathrm{d} 1$ and 3, the lactate produced by the LAB was not entirely consumed by $D$. hansenii (its concentration was low in this period). Consequently, the lactate concentration increased, and this evolution was well described by the model.

Concerning the final lactate concentration on d 14 , large differences between the runs were noticed. The differences seemed closely related to the $\mathrm{RH}$ of the ripening chamber. Indeed, the final lactate concentration was low (between 50 and $250 \mathrm{mmol} / \mathrm{kg}$ ) for the runs carried out at $99 \% \mathrm{RH}$, and high (between 380 and 400 $\mathrm{mmol} / \mathrm{kg}$ ) for the runs carried out at $85 \% \mathrm{RH}$. This was due to the positive influence of a high $\mathrm{RH}$ on the metabolic activity of $D$. hansenii (Figure 6C) as reported by Payne and Bruce (2001).

For the runs carried out at $99 \% \mathrm{RH}$, for which $D$. hansenii metabolic activity was not limited by the hygrometry, it was observed that the lactate concentration on $\mathrm{d} 14$ was lower when the ripening temperature was higher: $297 \mathrm{mmol} / \mathrm{kg}$ in the rind for the run at $8^{\circ} \mathrm{C}$ and $20 \mathrm{mmol} / \mathrm{kg}$ for the run at $16^{\circ} \mathrm{C}$. This reflects the positive effect of a temperature increase on the metabolic activity of $D$. hansenii. The last 2 results confirm the results of Payne and Bruce (2001), which followed 4-mo incubations at 8 to $25^{\circ} \mathrm{C}$ of temperature and 93 to $100 \% \mathrm{RH}$ and found that the maximum increase in viable $D$. hansenii cell count occurred at $15^{\circ} \mathrm{C}$ and $100 \% \mathrm{RH}$.

The lactose transfer coefficient between the cheese compartments was nearly 4 times lower than that of lactate (Table 3 ). This is probably related to the difference between the molecular weight of lactose (342 g/ $\mathrm{mol})$ and of lactate $(90 \mathrm{~g} / \mathrm{mol})$ and to interactions with the complex cheese matrix.

\section{CONCLUSIONS}

A mechanistic model describing the growth of $D$. hansenii and LAB activity in relation to substrate consumption, as well as lactose and lactate transfer between the cheese core and rind, was built and experimentally validated. The model parameters were determined with small confidence intervals. The model succeeded in predicting $D$. hansenii growth as a function of the temperature and $\mathrm{RH}$ of the ripening chamber and the evolution of lactose and lactate concentrations during ripening. It also simulated curd acidification during the first $3 \mathrm{~d}$ and lactose and lactate final concentrations. The modeling RSE were satisfying when compared with the standard deviation of the repeated experiments. The average RSE of the validation runs were close to those of the calibration runs, indicating the generalization ability of the model to other operating conditions within the experimental design limits.

The model parameters suggest that $D$. hansenii growth and LAB activity was influenced by both temperature and $\mathrm{RH}$ of the ripening chamber. The assumption according to which the considered strain of $D$. hansenii consumed lactose for its growth and lactate for its maintenance appeared reasonable.

\section{REFERENCES}

Aldarf, M., F. Fourcade, A. Amrane, and Y. Prigent. 2006. Substrate and metabolite diffusion within model medium for soft cheese in relation to growth of Penicillium camembertii. J. Ind. Microbiol. Biotechnol. 33:685-692.

Barba, D., F. Beolchini, G. Del Re, G. Di Giacomo, and F. Veglio. 2001. Kinetic analysis of Kluyveromyces lactis fermentation on whey: Batch and fed-batch operations. Process Biochem. 36:531-536.

Bastin, G., and D. Dochain. 1990. On-line estimation and adaptive control of bioreactors. Elsevier, Amsterdam, the Netherlands.

Biazar, J., M. Tango, E. Babolian, and R. Islam. 2003. Solution of the kinetic modeling of lactic acid fermentation using Adomian decomposition method. Appl. Math. Comput. 144:433-439.

Bockelmann, W., and T. Hoppe-Seyler. 2001. The surface flora of bacterial smear-ripened cheeses from cow's and goat's milk. Int. Dairy J. 11:307-314.

Bockelmann, W., K. P. Willems, H. Neve, and K. H. Heller. 2005. Cultures for the ripening of smear cheeses. Int. Dairy J. 15:719-732.

Bonaïti, C., M. N. Leclercq-Perlat, E. Latrille, and G. Corrieu. 2004. Deacidification by Debaryomyces hansenii of smear soft cheeses ripened in controlled conditions: Influences of relative humidity and of temperature. J. Dairy Sci. 87:3976-3988.

Bury, K. 1999. Statistical distributions in engineering. Cambridge University Press, Cambridge, UK.

Eliskases-Lechner, F., and W. Ginzinger. 1995. The bacterial flora of surface-ripened cheeses with special regard to coryneforms. Lait 75:571-584. 
Frau, M., S. Simal, A. Femenia, E. Sanjuan, and C. Rosselo. 1999. Use of principal component analysis to evaluate the physical properties of Mahon cheese. Eur. Food Res. Technol. 210:73-76.

Gerla, P. E., and A. C. Rubiolo. 2003. A model for determination of multicomponent diffusion coefficients in foods. J. Food Eng. 56:401-410.

Ghaly, A. E., and A. A. El-Taweel. 1997. Kinetic modelling of continuous production of ethanol from cheese whey. Biomass Bioenerg. 12:461-472.

Ghaly, A. E., M. Kamal, and L. R. Correia. 2005. Kinetic modelling of continuous submerged fermentation of cheese whey for single cell protein production. Bioresour. Technol. 96:1143-1152.

Hassouna, M., and N. Guizani. 1995. Evolution de la flore microbienne et des caractéristiques physico-chimiques au cours de la maturation du fromage tunisien de type Camembert fabriqué avec du lait pasteurisé. Microbiol. Hyg. Aliment. 7:14-23.

Hongxu, N., and S. Gunasekaran. 1998. Food quality prediction with neural networks. Food Technol. 52:60-65.

Horiuchi, J., T. Shimada, H. Funahashi, K. Tada, M. Kobayashi, and T. Kanno. 2004. Artificial neural network model with a culture database for prediction of acidification step in cheese production. J. Food Eng. 63:459-465.

Jimenez-Marquez, S. A., J. Thibault, and C. Lacroix. 2005. Prediction of moisture in cheese of commercial production using neural networks. Int. Dairy J. 15:1156-1174.

Leclercq-Perlat, M. N., F. Buono, D. Lambert, H. E. Spinnler, and G. Corrieu. 2004. Controlled production of Camembert-type cheeses: Part I. Microbiological and physicochemical evolutions. J. Dairy Res. 71:346-354.

Leclercq-Perlat, M.-N., A. Oumer, J.-L. Bergere, H.-E. Spinnler, and G. Corrieu. 2000. Behavior of Brevibacterium linens and Debaryo- myces hansenii as ripening flora in controlled production of smear soft cheese from reconstituted milk: Growth and substrate consumption. J. Dairy Sci. 83:1665-1673.

Lortal, S., and M.-P. Chapot-Chartier. 2005. Role, mechanisms and control of lactic acid bacteria lysis in cheese. Int. Dairy J. 15:857-871.

Lues, J. F. R., and A. C. M. Bekker. 2002. Mathematical expressions for organic acids in early ripening of a Cheddar cheese. J. Food Comp. Anal. 15:11-17.

Marquardt, D. 1963. An algorithm for least-squares estimation of nonlinear parameters. SIAM J. Appl. Math. 11:431-441.

Pajonk, A. S., R. Saurel, and J. Andrieu. 2003. Experimental study and modeling of effective $\mathrm{NaCl}$ diffusion coefficients values during Emmental cheese brining. J. Food Eng. 60:307-313.

Paquet, J., C. Lacroix, and J. Thibault. 2000. Modeling of $\mathrm{pH}$ and acidity for industrial cheese production. J. Dairy Sci. 83:23932409.

Payne, C., and A. Bruce. 2001. The yeast Debaryomyces hansenii as a short-term biological control agent against fungal spoilage of sawn Pinus sylvestris timber. Biol. Control 22:22-28.

Poveda, J. M., A. Garcia, P. J. Martin-Alvarez, and L. Cabezas. 2004. Application of partial least squares (PLS) regression to predict the ripening time of Manchego cheese. Food Chem. 84:29-33.

Rattray, F. P., and P. F. Fox. 1999. Aspects of enzymology and biochemical properties of Brevibacterium linens relevant to cheese ripening: A review. J. Dairy Sci. 82:891-909.

Schepers, W., A. J. Thibault, and C. Lacroix. 2002. Lactobacillus helveticus growth and lactic acid production during $\mathrm{pH}$-controlled batch cultures in whey permeate/yeast extract medium. Part II: Kinetic modeling and model validation. Enzyme Microb. Technol. 30:187-194. 